Indonesian Joumal of Legality of Law
ISSN: $2477197 \times$
https:/postgraduate.universitasbosowa.acid

\title{
EFEKTIVITAS PENGAWASAN KOMISI PENYIARAN INDONESIA DAERAH SULAWESI SELATAN TERHADAP PEMILIHAN KEPALA DAERAH
}

\author{
Effectiveness of Supervision of the South Sulawesi Regional Indonesian Broadcasting Commission \\ on Election of Regional Heads in 2018
}

\author{
Herman Pelani ${ }^{1}$, Baso Madiong ${ }^{2}$, Zulkifli Makkawaru ${ }^{3}$ \\ ${ }^{1}$ Mahasiswa Program Studi Ilmu Hukum Program Pascasarjana Universitas Bosowa \\ ${ }^{2}$ Programj Studi Ilmu Hukum Universitas Bosowa
}

Email: hpelani25@gmail.com

Diterima: 08 Agustus 2019/Disetujui: 09 Desember 2019

\begin{abstract}
ABSTRAK
Tujuan penelitian ini adalah, untuk mengetahui pelaksanaan dan faktor yang mempengaruhi efektifitas pengawasan Komisi Penyiaran Indonesia Daerah Sulawesi Selatan terhadap Program Pemilihan Kepala Daerah Tahun 2018, dilaksanakan di Kantor Komisi Penyaiara Indonesia Daerah Sulawesi Selatan di Kota Makassar. Metode yang gunakan adalah metode kuantitatif dengan tujuan untuk menguji pelaksanaan pengawasan Komisi Penyiaran Indonesia Daerah Sulawesi Selatan terhadap program Pemilihan Kepala Daerah tahun 2018. Hasil penelitian ini menunjukkan bahwa pelaksanaan pengawasan Komisi Penyiaran Indonesia Daerah Sulawesi Selatan terhadap program siaran Pemilihan Kepala Daerah tahun 2018 telah dilaksanakan, namun belum berjalan sebagaimana mestinya. Adapaun faktor-faktor yang memengaruhi efektivitas pelaksanaan pengawasan Komisi Penyiaran Indonesia Daerah Sulawesi Selatan terhadap program siaran Pemilihan Kepala Daerah tahun 2018 yaitu kurangnya sarana dan prasarana, kurangnya sumber daya manusia staf pengawas siaran (monitoring) dan sanksi hukum yang tidak memberikan efek jera kepada lembaga penyiaran yang melakukan pelanggaran.
\end{abstract}

Kata Kunci: Pengawasan, Komisi Penyiaran, Pemilihan Kepala Daerah

\section{ABSTRACT}

The purpose of this study was to determine the implementation and the factors that influence the effectiveness of the South Sulawesi Regional Indonesian Broadcasting Commission's supervision of the 2018 Regional Election Program, carried out at the South Sulawesi Regional Indonesian Commissioner's Office in Makassar. The method used is a quantitative method with the aim of testing the implementation of the supervision of the South Sulawesi Regional Indonesian Broadcasting Commission on the Regional Head Election program in 2018. The results of this study shows that the implementation of the supervision of the South Sulawesi Regional Indonesian Broadcasting Commission on the Regional Head Election Broadcast Program in 2018 has been carried out, but it has not been running as it should. The factors that influence the effectiveness of the implementation of the South Sulawesi Regional Indonesian Broadcasting Commission's supervision of the Regional Election Broadcasting program in 2018 are the lack of facilities and infrastructure, the lack of human resources of broadcast supervisors (monitoring) and legal sanctions that do not provide a deterrent effect to broadcasters who committed the violation.

Keywords: Supervision, Broadcasting Commission, Regional Head Election.

\section{PENDAHULUAN}

Media massa merupakan sebuah sarana dan saluran resmi sebagai alat komunikasi untuk menyebarkan berita dan pesan kepada masyarakat luas dengan menggunakan alat-alat dalam komunikasi yang bisa menyebarkan pesan secara serempat, cepat kepada audiens yang luas dan heterogen (Madjid, 2017).

Memperoleh informasi merupakan hak asasi manusia setiap warga negara, sebagaimana yang disebutkan dalam Undang-Undang Dasar Negara Republik Indonesia Tahun 1945 Pasal 28 F yang berbunyi "setiap orang berhak untuk berkomu-nikasi dan memperoleh informasi untuk mengembangkan pribadi dan lingkungan sosialnya, serta berhak untuk men-cari, memperoleh, memiliki, menyimpan, me-ngolah dan menyampaikan informasi dengan menggunakan segala jenis saluran yang tersedia (Jimly, 2014;2015; Hendry dan Rach-mah, 2015).

Salah satu media yang banyak digunakan untuk menyebarkan informasi adalah lembaga penyiaran televisi, termasuk informasi terkait pemilihan kepala daerah. Dalam menyiarkan siaran pemilihan kepala daerah, kadangkala lembaga penyiaran televisi berpihak kepada salah satu pasangan calon sehingga merugikan pasangan lain dan masya- 
rakat. Masyarakat mendapatkan informasi yang tidak benar, tidak berimbang, sehingga dapat mempengaruhi pilihan mereka. Masyarakat bisa salah dalam memilih calon kepala daerah akibat informasi yang tidak benar tersebut (Aswar, 2010; Danrivanto, 2013).

Untuk menjaga netralitas media penyiaran televisi dalam menyiarkan program siaran Pilkada agar masyarakat mendapatkan informasi yang benar, maka penyiran tersebut harus diawasi (Fajlurrahman, 2018). Lembaga yang diberikan amanat oleh UU Penyiaran untuk melakukan pengawasan terhadap siaran di televisi adalah Komisi Penyaiara Indonesia (KPI) di Pusat dan Komisi Penyiaran Indonesia Daerah (KPID) di Daerah Provinsi. KPI dan KPID merupakan lembaga negara independen yang berwenang menyusun, mengawasi dan memberi sanksi yang terkait dengan penyiaran.

Dalam Pasal 8 UU Penyiaran disebutkan bahwa: (1) KPI sebagai wujud peran serta masyarakat berfungsi mewadahi aspirasi serta mewakili kepentingan masyarakat akan penyiaran; (2) Dalam menjalankan fungsinya sebagaimana yang dimaksud dalam ayat (1), KPI mempunyai wewenang: a. Menetapkan standar program siaran; b. Menyusun pera-turan dan menetapkan pedoman perilaku penyiaran; c. Mengawasi pelaksanaan peraturan dan pedoman perilaku penyiran serta standar program siaran; $d$. Memberikan sanksi terhadap pelanggaran peraturan dan pedoman perilaku penyiaran serta standar program siaran; e. Melakukan koordinasi dan/atau kerjasama dengan Pemerintah, lembaga penyiran dan masyarakat; (3) KPI mempunyai tugas dan kewajiban: a. Menjamin masyarakat untuk memperoleh in-formasi yang layak dan benar sesuai dengan hak asasi manusia; b. Ikut membantu pengaturan infrastruktur bidang penyiaran; c.Ikut membangun iklin persaingan yang sehat antar lembaga penyiaran dan industri terkait; d. Memelihara tatanan infor-masi nasional yang adil, merata, dan seimbang; serta e. Menampung, meneliti, dan menindaklanjuti aduan, sanggahan, serta kritik dan aspirasi masyarakat terhadap penyelenggaraan penyiaran; dan $\mathrm{f}$ (Judhariksawan, 2013; Gun, 2018).

Menyusun perencanaan pengembangan sumber daya manusia yang menjamin profesionalitas di bidang penyiran. Terkait dengan wewenang KPI menetapkan standar program siaran dan menyusun peraturan dan menetapkan pedoman perilaku penyiaran maka, KPI mengeluarkan Pera-turan Komisi Penyiaran Indonesia Nomor 01/P/03/2012 Tentang Pedoman Perilaku Penyiaran (P3) dan Peraturan Komisi Penyiaran Indonesia Nomor 02/P/03/2012 Tentang Standar Program Siaran (SPS) (Sumeizita, 2006;Topo, 2019).

Dalam Pasal 50 P3 disebutkan bahwa (1) Lembaga penyiaran wajib menyediakan waktu yang cukup bagi peliputan pemilihan umum dan/atau pemilihan umum kepala daerah, (2) Lembaga penyiaran wajib bersikap adil dan proporsional terhadap para peserta pemilihan umum dan/atau pemilihan umum kepala daerah, (3) Lembaga penyiaran tidak boleh bersikap partisan terhadap salah satu pemesta pemilihan umum dan /atau pemilihan umum kepala daerah; (4) Lembaga penyiaran tidak boleh menyiarkan program siaran yang didanai atau disponsori oleh peserta pemilihan umum dan/atau pemilihan umum kepala daerah; (5) Lembaga penyiaran wajib tunduk pada Peraturan PerundangUndangan serta Peraturan dan Kebijakan Teknis tentang Pemilihan Umum dan/atau Pemilihan Umum Kepala Daerah yang ditetapkan oleh lembaga yang berwenang (KKPISS, 2018).

Sementara dalam SPS hal yang berkaitan dengan Pilkada disebutkan dalam Pasal 71 yang berbunyi: (1) Program siaran wajib menyediakan waktu yang cukup bagi peliputan Pemilihan Umum dan/atau Pemilihan Umum Kepala Daerah. (2) Program siaran wajib bersikap adil dan proporsional terhadap para peserta pemilihan umum dan/atau pemilihan umum kepala daerah, (3) Proram siaran dilarang memihak salah satu peserta Pemilihan Umum dan/atau Pemilihan Umum Kepala Daerah; (4) Program siaran dilarang dibiayai atau disponsori oleh peserta pemilihan umum dan/atau pemilihan umum kepala daerah, kecuali dalam bentuk iklan, (5) Program siaran wajib tunduk pada peraturan perundangundangan serta peraturan dan kebijakan teknis tentang pemilihan umum dan/atau pemilihan umum kepala daerah yang ditetapkan oleh lembaga yang berwenang, (6) Program siaran iklan kampanye tunduk pada peraturan perundangundangan, serta peraturan dan kebijakan teknis tentang kampanye yang ditetapkan oleh lembaga yang berwenang.

Tujuan penelitian ini adalah: (1) untuk mengetahui pelaksanaan pengawasan Komisi Penyiaran Indonesia Dae-rah Sulawesi Selatan terhadap Program Pemilihan Kepala Daerah Tahun 2018, dan (2) untuk mengetahui faktor yang memengaruhi efektivitas pengawasan Komisi Penyiaran Indonesia Daerah Sulawesi Selatan terhadap Program Pemi-lihan Kepala Daerah Tahun 2018.

\section{METODE}

Penelitian ini merupakan tipe penelitian deskriptif kualitatif, karena dalam penelitian ini mendeskripsikan pengawasan yang dilakukan oleh Komisi Penyiaran Indonesia Daerah Sulawesi Selatan terkait dengan program siaran pemilihan kepala daerah (pilkada) yang dilakukan oleh lembaga penyiran televisi di Sulawesi Selatan.

Menurut Zainuddin Ali (2014:105) penelitian yuridis normatif yang bersifat kualitatif, adalah penelitian yang mengacu pada norma hukum yang terdapat dalam peraturan perundang-undangan dan putusan pengadilan serta normanorma yang hidup dan berkembang dalam masyarakat.

Dalam penelitian ini data yang digunakan adalah data primer, yaitu data yang diperoleh langsung dari sumbernya, baik melalui wawancara, observasi, maupun laporan dalam bentuk dokumen tidak resmi yang kemudian diolah oleh peneliti. Sedangkan data sekunder, yaitu data yang diperoleh dari dokumen-dokumen resmi, buku-buku yang berhubu-ngan dengan objek penelitian, hasil penelitian dalam bentuk laporan, skripsi, tesis, disertasi, dan peraturan perundang-undangan.

Pengumpulan data dilakukan dengan cara wawancara (interview), yaitu dengan melakukan tanya jawab kepada pihak-pihak yang terkait dengan pengawasan Komisi Penyiaran Indonesia Daerah Sulawesi Selatan terhadap program pemilihan Kepala Daerah tahun 2018

\section{HASIL DAN PEMBAHASAN}

\section{Pengawasan Komisi Penyiaran Indonesia Daerah Sulawesi Selatan terhadap Program Pemilihan Ke- pala Daerah tahun 2018}

Komisi Penyiaran Indonesia Daerah (KPID) Sulawesi Selatan Sebagai lembaga 46egara independen yang diberikan kewenangan untuk mengawasi pelaksanaan peraturan dan 
pedoman perilaku penyiaran dan satndar program siaran di Daerah Provinsi Sulawesi Selatan. Salah satu yang menjadi objek pengawasan KPID Sulawesi Selatan yang disebutkan dalam regulasi adalah terkait dengan siaran Pemilihan Umum dan Pemilihan Umum Kepala Daerah.

Tahun 2018 di Sulawesi Selatan ada 13 (tiga belas) Pemilihan Kepala Daerah (Pilkada) serentak. Yang terdiri dari 1 (satu) Pemilihan Calon Gubernur dan Calon Wakil Gubernur Sulawesi Selatan, 9 (sembilan) Pemilihan Calon Bupati dan Calon Wakil Bupati yang terdiri atas Kabupaten Bone, Kabupaten Sinjai, Kabupaten Jeneponto, Kabupaten Bantaeng, Kabupaten Sidrap, Kabupaten Enrekang, Kabupaten Wajo, Kabupaten Luwu, Kabupaten Pinrang, serta 3 (tiga) Pemilihan Calon Walikota dan Wakil Walikota terdiri dari Kota Parepare, Kota Palopo, Kota Makassar.

Adapun jumlah Lembaga Penyiaran setiap daerah di Sulawesi Selatan yang Berizin Komisi Penyiaran Indonesia Daerah Sulawesi Selatan Update Februari 2018 dapat dilihat pada pada Tabel 1 di bawah ini.

\section{Tabel 1}

Jumlah Lembaga Penyiaran Yang Berizin Komisi Peyiaran Indonesia Daerah Sulawesi Selatan

\begin{tabular}{|c|c|c|c|c|}
\hline \multirow[b]{2}{*}{ No. } & \multirow{2}{*}{$\begin{array}{c}\text { Daerah } \\
\text { Kabupaten/Kota }\end{array}$} & \multicolumn{3}{|c|}{ Jumlah Lembaga Penyaiaran } \\
\hline & & Televisi & $\begin{array}{c}\text { TV } \\
\text { Kabel }\end{array}$ & Radio \\
\hline 1 & Makassar & 9 & 7 & 19 \\
\hline 2 & Maros & - & 1 & 1 \\
\hline 3 & Gowa & 6 & - & - \\
\hline 4 & Pangkep & - & 1 & - \\
\hline 5 & Parepare & 2 & 1 & 3 \\
\hline 6 & Pinrang & - & - & 3 \\
\hline 7 & Sidrap & - & 2 & - \\
\hline 8 & Bantaeng & - & 1 & 1 \\
\hline 9 & Takalar & 4 & - & 2 \\
\hline 10 & Bulukumba & 1 & 4 & 2 \\
\hline 11 & Sinjai & 1 & - & 1 \\
\hline 12 & Bone & 1 & 3 & 1 \\
\hline 13 & Wajo & - & 3 & 1 \\
\hline 14 & Soppeng & - & 1 & 1 \\
\hline 15 & Selayar & - & 2 & 1 \\
\hline 16 & Enrekang & - & 1 & - \\
\hline 17 & Tana Toraja & - & - & - \\
\hline 18 & Toraja Utara & - & 1 & - \\
\hline 19 & Palopo & 1 & 2 & 4 \\
\hline 20 & Luwu & - & 1 & - \\
\hline 21 & Luwu Timur & - & 1 & - \\
\hline 22 & Luwu Utara & - & 1 & 1 \\
\hline & $\begin{array}{l}\text { umlah Lembaga } \\
\text { Penyiaran }\end{array}$ & 25 & 33 & 41 \\
\hline
\end{tabular}

Sumber: Diolah data KPID Sulsel 2018

Berdasarkan Tabel 1 tersebut diketahui bahwa di Sulawesi Selatan cukup banyak lembaga penyiaran berizin yang dapat menyiarkan program siaran Pemilihan Kepala Daerah. Ada 25 (dua puluh lima) lembaga penyiaran televisi, 33 (tiga puluh tiga) lembaga penyiaran berlangganan (TV kabel) dan 41 (empat puluh satu) lembaga penyiaran radio. Jadi total keseluruhan lembaga penyiaran yang berizin yang dapat menyiarkan program Pilkada tahun 2018 di Sulsel ada 99 (sembilan Puluh sembilan). Selain itu, mungkin ada lembaga penyiaran yang tidak berizin yang mungkin saja menyiarkan program siaran Pilkada secara ilegal yang juga harus diawasi oleh KPID Sulsel. Ini pun harus mendapatkan pengawasan yang serius oleh KPID Sulsel demi terciptanya penyiaran yang yang sesuai dengan amanat UU Penyiaran untuk memperkukuh integrasi nasional, terbinanya watak dan jati diri bangsa yang beriman dan bertakwa, mencerdaskan kehidupan bangsa, memajukan kesejahteraan umum, dalam rangka membangun masyarakat mandiri, demokratis, adil dan sejahtera serta menumbuhkan industri penyiaran Indonesia.

Pengawasan yang dilakukan oleh KPID Sulsel dilakukan oleh staf staf pengawas isi siaran (monitoring) dengan menonton semua program siaran televisi yang terkait dengan program siaran Pilkada. Apabila ada pelanggaran maka monitoring mencatat pada lembaran pemantauan secara detail. Mulai dari Stasiun TV, hari,tanggal, dan bulan Program Acara (Talkshow, Iklan, Berita), Waktu Tayang, Narasumber (Talkshow dan Berita) Tema Talkshow/Dialog dan Deskripsi Tayangan.

Setelah dicatat dan dideskripsikan, tayangan yang terindikasi melanggar oleh monitoring, lalu dibawa ke anlis untuk dianalisis untuk memastikan apa betul itu sebuah pelanggaran atau bukan. Apabila menurut analis itu betul merupakan pelanggaran, maka analis akan mencari pasal apa saja yang dilanggar dan selanjutnya menyampaikan ke Komisioner untuk menentukan jenis pelanggaran dan sanksi yang akan diberikan kepada lembaga penyiaran yang melakukan pelanggaran tersebut.

Ada tiga fokus pengawasan yang dilaukan oleh KPID Sulsel pada lembaga penyiaran yang menyajikan program pemilihan kepala daerah yaitu sebagai berikut:

\section{a. Pengawasan Pemberitaan}

Pemetaan Pemberitaan Pilwalkot Makassar dan Pilgub Sulsel 2018 yang ditayangkan lembaga penyiaran televisi selama kampanye terbuka dapat dilihat pada Tabel 2.

Tabel 2

Pemetaan Pemberitaan Pilwalkot Makassar dan Pilgub Sulsel di Televisi Tahun 2018

\begin{tabular}{lccc}
\hline Nama Paslon Pilwalkot Makassar & Positif & Negatif & Netral \\
\hline Dani Pomanto / Kotak Kosong & 67 & 206 & \\
Munafri Arifuddin & 382 & 27 & \\
\hline slon Pilgub Sulsel & & & \\
\hline Nurdin Halid & 44 & 0 & \\
Agus Arifin Nu'mang & 17 & 0 & \\
Nurdin Abdullah & 26 & 0 & \\
Ichsan Yasin Limpo & 33 & 18 & \\
Netral & & & 899 \\
\hline
\end{tabular}

Sumber: KPID sulsel tahun 2018

Adapun yang menjadi sumber berita Pilgub Sulsel dan Pilwalkot Makassar di lembaga penyiaran televisi selama masa kampanye terbuka dapat dilihat pada Tabel berikut ini. (Tabel 3). 
Tabel 3

Sumber Berita Pilwalkot Makassar dan Pilgub Sulsel di Televisi Tahun 2018

\begin{tabular}{clc}
\hline No & \multicolumn{1}{c}{ Sumber Berita } & Frekuensi \\
\hline 1 & Paslon Dani Pomanto / Kotak & 28 \\
& Kosong & \\
2 & Paslon Munafri Arifuddin & 72 \\
3 & Paslon Nurdin Halid & 20 \\
4 & Paslon AgusTBAgus Arifin & 7 \\
& Nu'mang & \\
5 & Paslon Nurdin Abdullah & 14 \\
6 & Paslon Ichsan Yasin Limpo & 21 \\
7 & Akademisi/Pengamat & 106 \\
8 & Tim Pemenangan Dani Pomanto & 40 \\
9 & Tim Pemenangan Munafri & 177 \\
& Arifuddin & \\
10 & Tim Pemenangan Nurdin Halid & 17 \\
11 & Tim Pemenangan Agus Arifin & 7 \\
& Nu'mang & \\
12 & Tim Pemenangan Nurdin & 5 \\
& Abdullah & \\
13 & Tim Pemenangan Ichsan yasin & 954 \\
& Limpo & \\
14 & Peserta Pemilu Kabupaten & 17 \\
15 & KPU SULSEL \& & \\
& Kabupaten/Kota & \\
16 & Bawaslu Kabupaten/Kota & \\
19 & Ranwaslu Kabupaten/Kota & \\
\hline
\end{tabular}

Sumber: KPID Sulsel tahun 2018

Berdasarkan tabel 4 di atas, analis KPID Sulsel Muhammad Iswar Ramadhan menjelaskan temuannya. Pertama, frekuensi pemberitaan pada Pemilihan Walikota Makassar lebih banyak didominasi oleh pasangan Munafri Arifuddin dan Rahmatika Dewi (Appi-Cicu) dengan tone positif. Hal ini berbanding terbalik dengan Pasangan Dani Pomanto-Indira Mulyasari (DIAMI) yang mendapat tone negatif dengan jumlah yang besar. Kedua, Isu utama yang membuat tone negatif pasangan DIAMI cukup besar adalah adanya isu penyalahgunaan kekuasaan oleh calon Dani Pomanto yang juga merupakan incumbent Walikota Makassar. Ketiga, pada pemberitaan pemilihan Gubernur Sulawesi Selatan cenderung merata, hal ini diakibatkan memang minimnya porsi pemberitaan terhadap para calon gubernur dan timnya pada saat kampanye terbuka yang dimulai pada 15 Februari 2018.

\section{b. Pengawasan Penyiaran}

Pemetaan penyiaran Pilwalkot Makassar dan Pilgub Sulsel selama masa kampanye terbuka. (Tabel 4). Adapun yang menjadi Narasumber Dialog Pilgub Sulsel dan Pilwalkot Makassar di media televisi pada masa kamanye terbuka (Tabel 5). Berdasarkan Table 5 dan Tabel 6, analis KPID Sulsel Muhammad Iswar Ramadhan menjelaskan bah-wa pertama, frekuensi penyiaran pada pemilihan Walikota Makassar cenderung netral, walaupun pada beberapa topik pasangan calon DIAMI (sebelum didiskualifikasi) mendapat lebih banyak tone negatif. Kedua, isu yang kerap diangkat pada aspek penyiaran yang juga membuat tone negatif pasangan DIAMI adalah adanya isu penyalahgunaan kekuasaan oleh calon Dani Pomanto yang juga merupakan incumbent
Walikota Makassar. Ketiga, pada aspek penyiaran pemilihan Gubernur Sulawesi Selatan juga cenderung netral, karena isu pemilihan gubernur memang jarang diangkat pada aspek penyiaran di beberapa lembaga penyiaran di Sulawesi Selatan.

Tabel 4

Pemetaan Penyiaran (Dialog/Talkshow) Pilwalkot Makassar dan Pilgub di Televisi Sulsel Tahun 2018

\begin{tabular}{lccc}
\hline \multicolumn{1}{c}{$\begin{array}{c}\text { Nama Paslon Pilwalkot } \\
\text { Makassar }\end{array}$} & Positif & Negatif & Netral \\
\hline $\begin{array}{l}\text { Dani Pomanto / Kotak Kosong } \\
\text { Munafri Arifuddin }\end{array}$ & 6 & 10 & \\
Nama Paslon Pilgub Sulsel & 3 & 0 & \\
Nurdin Halid & & & \\
Agus Arifin Nu'mang & 0 & 0 & \\
Nurdin Abdullah & 2 & 0 & \\
Ichsan yasin Limpo & 2 & 0 & \\
Netral & 0 & 0 & \\
\hline Sumber: data KPID Sulsel 2018 & & & \\
\hline
\end{tabular}

Tabel 5

Narasumber Dialog/Talkshow Pilwalkot Makassar dan Pilgub Sulsel di Televisi Tahun 2018

\begin{tabular}{|c|c|c|}
\hline No. & Narasumber Dialog/Talkshow & Frekuensi \\
\hline 1 & $\begin{array}{l}\text { Paslon Dani Pomanto / Kotak } \\
\text { Kosong }\end{array}$ & 2 \\
\hline 2 & Paslon Munafri Arifuddin & 0 \\
\hline 3 & Paslon Nurdin Halid & 1 \\
\hline 4 & Paslon Agus Arifin Nu'mang & 1 \\
\hline 5 & Paslon Nurdin Abdullah & 1 \\
\hline 6 & Paslon Ichsan Yasin Limpo & 1 \\
\hline 7 & Akademisi/Pengamat & 72 \\
\hline 8 & Tim Pemenangan Dani Pomanto & 2 \\
\hline 9 & $\begin{array}{l}\text { Tim Pemenangan Munafri } \\
\text { Arifuddin }\end{array}$ & 11 \\
\hline 10 & Tim Pemenangan Nurdin Halid & 1 \\
\hline 11 & $\begin{array}{l}\text { Tim Pemenangan Agus Arifin } \\
\text { Nu'mang }\end{array}$ & 2 \\
\hline 12 & $\begin{array}{l}\text { Tim Pemenangan Nurdin } \\
\text { Abdullah }\end{array}$ & 0 \\
\hline 13 & $\begin{array}{l}\text { Tim Pemenangan Ichsan yasin } \\
\text { Limpo }\end{array}$ & 1 \\
\hline 14 & Peserta Pemilu Kabupaten & 11 \\
\hline 15 & $\begin{array}{l}\text { KPU SULSEL \& } \\
\text { Kabupaten/Kota }\end{array}$ & 31 \\
\hline 16 & Bawaslu Kabupaten/Kota & 9 \\
\hline 17 & Panwaslu Kabupaten/Kota & 1 \\
\hline 18 & Redaksi & 13 \\
\hline 19 & Lainnya & 19 \\
\hline
\end{tabular}

Sumber: data KPID Sulsel 2018

\section{c. Pengawasan Iklan}

Adapun Pemetaan Iklan Pilwalkot Makassar dan Pilgub Sulsel yang ditayangkan dilembaga penyiaran Televisi pada masa kampanye terbuka dapat dilihat Tabel 6. 
Tabel 6

Pemetaan Iklan Pilwalkot dan Pilgub Sulsel di Televisi Tahun 2018

\begin{tabular}{lccc}
\hline Nama PaslonPilwalkot Makassar & Positif & Negatif Netral \\
\hline Dani Pomanto / Kotak Kosong & 0 & 0 & \\
Munafri Arifuddin & 42 & 0 & \\
Nama Paslon Pilgub Sulsel & & & \\
Nurdin Halid & 6 & 0 & \\
Agus Arifin Nu'mang & 6 & 0 & \\
Nurdin Abdullah & 6 & 0 & \\
Ichsan yasin Limpo & 6 & 0 & \\
Netral & & & 112 \\
\hline
\end{tabular}

Sumber: data KPID Sulsel 2018

Adapaun yang menjadi pengiklan pada Pilgub Sulsel dan Pilwalkot Makassar pada masa kampanye terbuka di lembaga penyiaran televisi yang ditayangkan pada Bulan Februari sampai dengan Bulan Juni 2018 dapat dilihat pada Tabel 7.

Tabel 7

Pengiklan pada Pilwalkot Makassar dan Pilgub Sulsel di Televisi Tahun 2018

\begin{tabular}{clc}
\hline No & \multicolumn{1}{c}{ Pengiklan } & Frekuensi \\
\hline 1 & Paslon Dani Pomanto / Kotak Kosong & 0 \\
2 & Paslon Munafri Arifuddin & 42 \\
3 & Paslon Nurdin Halid & 6 \\
4 & Paslon Agus Arifin Nu'mang & 6 \\
5 & Paslon Nurdin Abdullah & 6 \\
6 & Paslon Ichsan Yasin Limpo & 6 \\
7 & Akademisi/Pengamat & 0 \\
8 & Tim Pemenangan Dani Pomanto & 0 \\
9 & Tim Pemenangan Munafri Arifuddin & 0 \\
10 & Tim Pemenangan Nurdin Halid & 0 \\
11 & Tim Pemenangan Agus Arifin Nu'mang & 0 \\
12 & Tim Pemenangan Nurdin Abdullah & 0 \\
13 & Tim Pemenangan Ichsan yasin Limpo & 0 \\
14 & Peserta Pemilu Kabupaten & 0 \\
15 & KPU SULSEL \& Kabupaten/Kota & 84 \\
16 & Bawaslu Kabupaten/Kota & 22 \\
17 & Panwaslu Kabupaten/Kota & 0 \\
18 & Redaksi & 0 \\
19 & Lainnya & 0 \\
\hline
\end{tabular}

Sumber: Data KPID Sulsel 2018

Berdasarkan Tabel 7 menunjukkan bahwa, analis KPID Sulsel, Muhammad Iswar Ramadhan mengatakan bahwa sebaran iklan selama kampanye terbuka dan masa kampanye di media massa khususnya televisi pada kontestasi pemilihan Walikota Makassar 2018 didominasi oleh pasangan calon Munafri Arifuddin dan Rahmatika Dewi (Appi-Cicu) hal ini dikarenakan gugurnya pasangan Dani Pomanto-Indira Mulyasari (DIAMI) yang menjadi lawan tunggal dari pasangan calon Appi-Cicu. Sedangkan pada kontestasi pemilihan gubernur cenderung netral. Iklan seluruh calon yang menampilkan visi misi hanya muncul sebanyak $6 \mathrm{kali}$, dimana iklan tersebut langsung menampilkan visi dan misi masing-masing calon dengan durasi yang sama.
Dari pengawasan yang dilakukan oleh KPID terhadap program siaran pemilihan Kepala Daerah tahun 2018, dapat disimpulkan disimpulkan bahwa Pertama, Selama periode kampanye terbuka hingga $\mathrm{H}-1$ pemilihan Walikota Makassar pada aspek pemberitaan dan penyiaran, pasangan calon Walikota Dani Pomanto dan Indira Mulyasari (DIAMI) mendapat tone negatif yang cukup besar dan berbanding terbalik dengan pasangan Munafri Arifuddin-Rahmatika Dewi (AppiCicu) yang cenderung mendapat tone positif. Sedangkan pada kontestasi pemilihan Gubernur Sulawesi Selatan pada aspek pemberitaan, penyiaran dan iklan relatif netral, tanpa adanya salah satu kandidat yang mendominasi. Kedua, distribusi Iklan pada pemilihan Walikota Makassar memang didominasi oleh pasangan Appi-Cicu, hal ini dikarenakan didiskualifikasinya pasangan Dani Pomanto dan Indira Mulyasari akibat penyalahgunaan wewenang saat menjabat sebagai Walikota Makassar. Ketiga, Tone negatif pasangan Dani Pomanto dan Indira Mulyasari (DIAMI) sebelum digugurkan oleh KPU, lebih banyak disumbang oleh Dani Pomanto. Keempat, Selama proses kampanye terbuka hingga pelaksanaan pemilihan kepala daerah serentak di Sulawesi Selatan, ada pelanggaran yang dilakukan oleh lembaga penyiaran. Dan kelima, Selama proses kampanye terbuka di lembaga penyiaran yang ada di Sulawesi Selatan, terdapat pelanggaran yang dilakukan oleh lembaga penyiaran. Diantaranya isu ketidak berimbangan lem-baga penyiaran yang dimana melanggar pasal 71 SPS Poin 2 terkait "Program siaran wajib bersikap adil dan proporsional terhadap para peserta Pemilihan Umum dan/atau Pemilihan Umum Kepala Daerah"

Dari data-data yang telah disajiakan tersebut, dapat dipahami bahwa Komisi Penyiaran Indonesia Daerah Sulawesi Selatan telah melakukan pengawasan terhadap siaran pemi-lihan Kepala Daerah tahun 2018. Namun tidak semua lembaga penyiaran televisi yang memiliki izin penyelenggaraan penyi-aran diawasi. Sehingga dalam pengawasan tersebut tidak bisa dipastiakan bahwa semua program siaran pilkada yang ada di Sulawesi selatan telah berjalan sesuai dengan regulasi yang ada. Karena luput dari pemantaun. Hanya pemilihan calon Walikota Makassar dan Pemilihan calon Gubernur dan Wakil Gubernur yang mendapatkan pemantauan.

Penyiaran yang dipantau saja masih sangat banyak pelanggaran ditemukan, apalagi yang tidak dipantau seperti yang ada di daerah lain di seluruh kabupaten/kota di Sulawesi Selatan. Apalagi ada daerah yang paslonnya adalah petahana yang boleh dibilang menguasai lembaga penyiaran di daerahnya. Sehingga sulit bagi pasangan calon lain untuk mendapatkan porsi yang sama dalam pemberitaan, dan penyiaran (dialog/talkshow) serta iklan pilkada. Sehingga hal tersebut tidak mencerminkan keadilan bagi semua pasangan calon yang ikut berkontestasi dalam pemilihan kepala daerah yang diadakan.

2. Faktor yang Memengaruhi Efektivitas Pengawasan Komisi Penyiaran Indonesia Daerah Sulawesi Selatan terhadap Program Pemilihan Kepala Daerah Tahun 2018

Adapun yang memengaruhi efektivitas pelaksanaan penga-wasan KPID Sulawesi Selatan terhadap program Pilkada tahun 2018 di Sulawesi Selatan ada beberapa faktor, yaitu: 


\section{a. Sarana dan Prasarana}

Sarana dan prasarana sangat penting keberadaannya untuk menunjang efektivitas kinerja sebuah lembaga. Kurangnya sarana dan prasarana akan memengaruhi atau menghambat pelaksanaan tugas sebuah lembaga, termasuk KPID Sulawesi selatan. Seperti yang sampaikan oleh ketua KPID Sulawesi Selatan Mattewakkan bahwa Peralatan yang dimiliki oleh KPID masih sangat minim apalagi untuk menjangkau Sulawesi Selatan yang terbilang cukup luas. Dengan peralatan yang kurang itu maka tidak semua daerah di sulsel ini dapat dipantau oleh tim monitoring miski di daerah ada lembaga penyiaran yang mungkin saja melakukan penyiaran terkait pilkada.

Kurangnya sarana pendukung yang dimiliki oleh KPID Sulsel dalam melakukan pengawasan terhadap penyairan yang dilakukan di daerah berdampak pada tidak efektifnya pengawasan. Tidak semua daerah yang menyelenggarakan Pilkada dapat terpantau. Daerah yang dipantau oleh KPID hanya penyiaran Pilwalkot Makassar dan Pilgub Sulsel yang disiar-kan oleh beberapa lembaga penyairan saja.

\section{b. Sumber Daya Manusia}

Sumberdaya manusia (staf monitoring) merupakan salah satu faktor penting dalam melakukan pengawasan terhadap siaran Pilkada karena merekalah yang mengamati langsung penyiaran sehingga, isi penyiaran tersebut diketahui apakah sudah sesuai dengan regulasi yang ada. Sehingga apabila ada pelanggaran, merupakan dasar bagi KPID Sulsel untuk memberikan sanksi sesuai dengan peraturan perundang-undangan yang berlaku.

Seperti yang sampaikan oleh ketua KPID Sulawesi Selatan Mattewakkan bahwa: tenaga pemantau yang jumlahnya sangat kurang pada pilkada tahun 2018. Hanya ada 8 tenaga pemantau (monitoring) dan 2 tenaga analis, sementara lembaga penyiaran di Sulawesi Selatan cukup banyak.

Dengan kurangnya staf monitoring yang melakukan pengawasan siaran Pilkada ini sangat berdampak pada efektivitas pengawasan karena tidak bisa memantau semua lembaga penyiaran yang ada di Sulawesi Selatan yang melakukan Pemilihan Kepala Daerah tahun 2018.

\section{c. Sanksi Hukum}

Undang-Undang Nomor 32 Tahun 2002 tentang Penyiaran (UU Penyiaran), Peraturan Komisi Penyiaran Indonesia Nomor 01/P/KPI/03/2012 tentang Pedoman Perilaku Penyiaran (P3), Peraturan Komisi Penyiaran Indonesia Nomor 02/P/KPI/2012 tentang Standar Program Siaran (SPS), menyebutkan akan adanya sanksi yang dapat diberikan kepada lembaga penyiraan televisi yang melakukan pelanggaran cukup banyak. UU Penyiaran menyebutkan adanya sanksi pidana dan juga sanksi administratif. Sementara P3 dan SPS (P3SPS) hanya menyebutkan sanksi administratif.

Dalam pandagan penulis ada beberapa jenis pelanggaran yang berpontesi dilakukan oleh lembaga penyiaran televisi dalam program siaran pemilihan kepala daerah yang dapat diberikan sanksi pidana. Pelanggaran tersebut misalnya pemberitaan yang sifatnya memfitna, menghasut, menyesatkandan membuat berita bohong (hoax). Dalam UU Penyiaran disebutkan pada Pasal 36 ayat (5) yang berbunyi isi siaran dilarang: a bersifat fitnah, menghasut, menyesatkan dan/atau bohong. Ancaman pidananya sebagaimana disebutkan dalam Pasal 57 UU penyairan adalah dipidana dengan pidana penjara paling lama 5 (lima) tahun dan/atau denda paling banyak $\mathrm{Rp}$ 1.000.000.000,00 (satu milyar rupiah) untuk penyiaran radio dan dipidana dengan pidana penjara 5 (lima tahun) dan/atau denda paling banyak Rp. 10.000.000.000,00 (sepuluh milyar) untuk penyiaran televisi.

Pemberitaan yang bersifat fitnah, menghasut, menyesatkan dan/atau bohong bisa saja dilakukan oleh lembaga penyiaran yang berpihak kepada paslon tertentu demi menjatuhkan citra pasangan lainnya. Jadi di sini dibutuhkan ketelitian KPID untuk melakukan pengawasan dan penegakan hukum agar tidak ada pelanggaran dalam program acara pilkada, baik berita, penyiaran dalam hal ini dialog dan talkshow serta iklan kampanye.

Selain itu, pelanggaran lain juga bisa berupa pembelian waktu siaran lembaga penyiaran televisi oleh paslon tertentu untuk kepentingannya dalam menyampaikan program yang akan mereka lakukan demi menarik dukungan masyarakat. Dalam Pasal 46 ayat (10) yang berbunyi bahwa "waktu siaran lembaga penyiaran dilarang dibeli oleh siapapun untuk kepentingan apapun, kecuali untuk siaran iklan. Ancaman pidana pelanggaran ini disebutkan pada Pasal 59 yang berbunyi setiap orang yang melanggar ketentuan sebagaimana dimaksud dalam Pasal 46 ayat (10) dipidana dengan pidana denda paling banyak Rp 200.000.000,00 (dua ratus juta rupiah) untuk penyiaran radio dan paling banyak Rp 2.000.000.000,00 (dua milyar rupiah) untuk penyiaran televisi.

Selain sanksi pidana lembaga penyiaran yang melakukan pelanggaran dapat pula diberikan sanksi administratif sebagaimana disebutkan pada Pasal 55 UU Penyiaran ayat (2) dan Bab XXXI SPS mengenai sanksi administratif. sanksi administratif itu dapat berupa:

a. Teguran tertulis;

b. Penghentian sementara mata acara yang bermasalah setelah melalui tahap tertentu;

c. Pembatasan durasi dan waktu siaran;

d. Denda administrative; dan

e. Pembekuan kegiatan untuk waktu tertentu;

f. Tidak diberi perpanjangan izin penyelenggaraan penyiaran.

Melihat begitu banyak sanksi yang bisa diberikan kepada lembaga penyiaran apabila melakukan pelanggaran, mestinya KPID Sulsel bisa menerapkan sanksi yang diberikan oleh UU tersebut. Jangan hanya memberikan sanksi yang ringan pada-hal sudah bisa diberikan sanksi yang membuat lembaga pe-nyiaran takut berbuat pelanggaran. Jangan sampai karena KPI tidak memberikan sanksi yang menjerakan lembaga penyi-aran, membuat masyarakat tidak percaya dan meng-harapkan pembubaran lembaga ini karena dianggap tidak melakukan apa-apa. Karena meski lembaga ini ada, namun kenyataannya pelangaran pun tetap berlangsung. (Zainuddin, 2014).

Meski banyak jenis sanksi yang dapat diberikan kepada lembaga penyiaran sesuai dengan tingkat kesalahannya, namun, KPID Sulsel dalam menjatuhkan sanksi kepada lembaga penyiaran saat pilkada 2018 hanya sanksi administratif berupa teguran tertulis. Tidak ada sanksi yang menjerakan. Sanksi admninistratif teguran tertulis tidak bisa menjerakan lembaga penyairan yang melakukan pelanggaran. Tidak ada pemberian sanksi yang menjerakan agar lembaga penyiaran televisi tidak berbuat pelanggaran. Padahal dari data yang ada diketahui bahwa lembaga penyiaran yang dipantau oleh KPID Sulsel sebagian besar kelihatnnya berpihak peda salah satu paslon tertentu (Morissan, 2015;Mahfud, 2017).

Sanksi teguran tertulis ini sangat ringan, sehingga tidak membuat lembaga penyiaran "takut" untuk melakukan pe- 
langgaran. Lebih celaka lagi bahkan lembaga penyiaran tetap melakukan pelanggaran yang telah mereka lakukan sebelumnya meski telah mendapatkan teguran. Harusnya KPID memberikan sanksi yang lebih berat apabila lembaga penyiaran telah melakukan pelanggaran berulang tampah mengindahkan teguran tertulis dari KPID sulsel.

Menurut Judhariksawan persolan yang kemudian lahir dari penerapan sanksi administratif ini anatara lain berkisar pada faktor kewenangan. Jika selama ini Komisi Penyiaran Indonesia hanya bertindak sebagai regulator, maka kewenangan eksekutor yang seharusnya juga melekat padanya tidak berlaku efektif secara keseluruhan. Sebagai contoh, teguranteguran tertulis yang telah diajukan oleh KPI tidak menjadi "alat jera" karena berbagai bentuk pelanggaran yang menjadi dasar teguran tersebut tetap saja dilakukan. Jika suatu acara diberikan sanksi administratif, hal itu tidak menghentikan penyelenggaraan penyiaran untuk tidak berbuat hal yang sama pada mata acara lainnya. (Zainuddin, 2014;Zainal, 2016).

Selain itu, mengenai sanksi pencabutan izin. Dikatakan oleh ketua KIPD Mattewakkan bahwa mengenai pencabutan izin penyelenggaraan penyiaran (IPP), KPI dan KPID cuma bisa memberikan rekomendasi. Yang melakukan pencabutan adalah Kementerian Komunikasi dan Informasi. Dari segi pencabutan dan pemberian izin penyelenggaraan penyiaran (IPP) KPID cuma bisa merekomendasikan kepada pemerintah dalam hal ini Kementerian Komunikasi dan Informsi. Di sini terlihat kelemahan sifat eksekutorial KPID dari segi perizinan yang harus berbagi dengan pemerintah. Sehingga hali ini bisa saja menyebabkan lembaga penyiaran tidak merasa takut pada kewenangan KPID karena masih tereduksi oleh peran pemerintah mengeluarkan Izin Penyelenggaraan Penyiaran (IPP).

Dengan demikian, wajar saja jika sampai saat ini ancaman sanksi administratif berupa pencabutan izin penyelenggaraan penyiaran masih sebatas ancaman tak menjerakan dan tak menakutkan bagi lembaga penyiaran.

Karena selama ini yang diberikan hanya sanksi administrasi teguran tertulis yang tidak menjerakan bagi lembaga penyiaran yang melakukan pelanggaran, maka ke depan perlu ada sanksi yang lebih memberikan efek jera. Sanksi itu berupa pencabutan izin penyelenggaraan penyiaran yang memang telah melakukan pelanggaran berat. Sanksi pencabutan izin penyelenggaraan penyiaran (IPP) harus menjadi kewenangan KPI di Pusat dan KPID di Daerah.

Ke depan KPI dan KPID harus diberikan kewenangan yang lebih memadai. Sebagai lembaga negara independen di bidang penyiaran yang dibentuk berdasarkan Undang-Undang Nomor 32 Tahun 2002 tentang Penyiaran (UU Penyiaran), KPI dan KPID tidak boleh hanya seperti "macan ompong" cuma kelihatan menakutkan tapi sejatinya tidak bisa menggigit. Dengan demikian, tentu dibutuhkan UU baru yang mengatur hal tersebut. Karena UU yang sekarang belum mengakomodir kewenangan tersebut. Olehnya itu revisi UU penyiaran menjadi hal yang ungen dilakukan demi KPI dan KPID yang semakin efektif dan berwibawa dalam mengawasi penyiaran di Indonesia.

\section{KESIMPULAN}

Berdasarkan hasil penelitian dapat disimpulkan bahwa, Pelaksanaan pengawasan Komisi Penyiaran Indonesia Daerah Sulawesi Selatan terhadap program Pemilihan Kepala Daerah tahun 2018 telah dilaksanakan, namun belum berjalan seba-gaimana mestinya; dan Pelaksanaan pengawasan Komisi Penyiaran Indonesia Daerah Sulawesi Selatan terhadap pro-gram Pemilihan Kepala Daerah tahun 2018 belum berjalan secara efektif, antara lain : kurangnya sarana dan prasarana, kurangnya sumber daya manusia staf pengawas siaran (moni-toring) dan sanksi hukum yang diberikan kepada lembaga penyiran yang melakukan pelnggaran tidak memberikan efek jera kepada lembaga penyiaran yang melakukan pelanggaran kembali.

\section{DAFTAR PUSTAKA}

Aswar, Hasan. (2010). Panorama Penyiaran Di Sulawesi Selatan. PT. Umitoha Ukhuwah Grafika Makassar Kerjasama dengan KPID Sulsel, Makassar.

Danrivanto Budhijanto. (2013). Hukum Telekomunikasi, Penyiaran dan Teknologi Informasi: Regulasi dan Konvergensi. Refika Aditama, Bandung.

Fajlurrahman, Jurdi. (2018). Pengantar Hukum Pemilihan Umum. Prenadamedia Group, Jakarta.

Gun Gun, Heryanto. (2018). Media Komunikasi Politik: Relasi Kuasa Media di Panggung Politik. IRCiSoD, Yogjakarta.

Hendry Subiakto dan Rachmah. (2015). Komunikasi Politik, Media, dan Demokrasi. Prenadamedia Group, Jakarta.

Jimly Asshiddiqie. (2014). Pengantar Hukum Tata Negara. PT. RajaGrafindo Persada, Jakarta.

(2015). Hukum Tata Negara dan PilarPilar Demokrasi. Sinar Grafika, Jakarta.

Judhariksawan. (2013). Hukum Penyiaran. PT. RajaGrafindo Persada, Jakarta.

[KKPIDSS] Keputusan Komisi Penyiaran Indonesia Daerah Sulawesi Selatan. (2018). Nomor 240/SK/KPID-SS/ 03/2018 Tentang Petunjuk Pelaksanaan Terkait Perlindungan Kepentingan Publik Terhadap Pengawasan Pemberitaan, Penyiaran dan Iklan Kampanye Pemilihan Gubernur dan Wakil Gubernur, Bupati dan Wakil Bupati, dan/atau Walikota dan Wakil Walikota Melalui Lembaga Penyiaran.

Madjid, S. A. B. (2017). Aktivitas Spin Doctor Menjelang Pemilihan Gubernur 2018 di Provinsi Sulawesi Selatan (Doctoral dissertation, Universitas Islam Negeri Alauddin Makassar).

Moh. Mahfud MD. (2017). Politik Hukum di Indonesia. PT. RajaGrafindo Persada, Jakarta.

Morissan. (2015). Teori Komunikasi Individu Hingga Massa. Prenadamedia Group, Jakarta.

Sodikin. (2014). Hukum Pemilu: Pemilu Sebagai Praktek Ketatanegaraan. Gramata Publising, Bekasi.

Sumeizita Suarman. (2006). Media dan Pemilu, Deskripsi untuk Pilkada. Komisi Penyiaran Daerah Sulawesi Selatan, Makassar.

Topo Santoso dan Ida Budhiati. (2019). Pemilu di Indonesia: Kelembagaan, Pelaksanaan dan Pengawasan. Sinar Gra-fika, Jakarta.

Zainal Arifin Mochtar. 2016. Lembaga Negara Independen: Dinamika Perkembangan dan Urgensi Penataannya Kembali Pasca-Amandemen Konstitusi. Rajawali Pers, Jakarta.

Zainuddin Ali. 2014. Metode Penelitian Hukum, Sinar Grafika, Jakarta. 